\title{
GLAUBER ROCHA E HIROSHIMA MON AMOUR: NOTAS SOBRE UM AMOR ECLIPSADO
}

http://dx.doi.org/10.11606/issn.2237-1184.v0i31p113-132

Mateus Araújo ${ }^{\mathrm{I}}$

\section{RESUMO}

O artigo reexamina a recepção crítica de Hiroshima mon amour por Glauber Rocha, que lhe consagrou dois artigos específicos em 1960-61, e deixou uma série considerável de referências ao filme ou a Resnais em uma trintena de outros textos (sobre outros filmes e cineastas), basicamente na década de 1960, mas também, em número menor, na seguinte. Neste percurso, discute o entusiasmo com o qual Glauber acolhe o filme no calor da hora, mas que parece refluir com o passar dos anos, num eclipse gradual do qual o sintoma mais significativo é a ausência daqueles dois artigos no sumário d'O Século do Cinema, seu livro preparado antes da morte sobre o cinema mundial.

\section{ABSTRACT}

This paper reexamines the critical reception of Hiroshima mon amour by Glauber Rocha, who consecrated two specific articles to it in 1960-61, and left a lot of references to the film or to Resnais in thirty other texts (on other subjects), basically in the 1960s, but also later. In this journey, we discuss the enthusiasm with which Rocha welcomes the film when it was released in Brazil, but which seems to weaken over the years, in a gradual eclipse of which the most significant symptom is the absence of those two articles in the summary of $\mathrm{O}$ Século do Cinema (1983), his book on world cinema prepared before death and published posthumously.

\section{PALAVRAS-CHAVE:}

Hiroshima mon amour;

Glauber Rocha;

Alain Resnais;

cinema moderno.

\section{KEYWORDS}

Hiroshima mon amour; Glauber Rocha; Alain Resnais; modern cinema.

\footnotetext{
I Universidade de São Paulo, São Paulo, São Paulo, Brasil.
} 
rimeiro longa-metragem de Alain Resnais, Hiroshima mon amour consolidava, em 1959, dois traços salientes de sua carreira já estabelecida de cineasta: a relação densa com a literatura e a tematização de traumas coletivos produzidos pela guerra. Em filmes anteriores, ele já integrara na banda sonora, com muita desenvoltura, versos de Paul Éluard e Raymond Queneau em Guernica (1950) e Le chant du styrène (1958), assim como um texto em prosa de Jean Cayrol em Nuit et brouillard (1955). E já se voltara, em dois deles, para episódios particularmente traumáticos da história do século XX: a destruição de Guernica pelos nazi-fascistas, em 1937 (em Guernica), e os campos de concentração nazistas (em Nuit et brouillard).

Insistindo neste universo de questões, ao qual voltaria em filmes posteriores, ${ }^{1}$ Resnais convida para uma nova parceria literária, agora em torno da bomba de Hiroshima (assunto proposto pelos produtores), Marguerite Duras, escritora já reconhecida na época, mas pouco experimentada em cinema. Em estreita colaboração com o cineasta e com Gérard Jarlot, ela escreve uma história de amor entre um homem japonês, "engenheiro ou arquiteto", e uma atriz francesa (também traumatizada, em seu próprio país, pela Segunda Guerra), que visitava Hiroshima para uma filmagem sobre a paz. ${ }^{2} \mathrm{O}$ cineasta a utiliza num registro que conjuga a ficção sobre o casal de amantes e trechos semidocumentais referidos à memória da destruição causada pelo bombardeio da cidade japonesa. Se os personagens (sobretudo a mulher) lidavam com a necessidade vital de elaborar psiquicamente o trauma da guerra para exorcizá-lo, fazer o luto e seguir vivendo, o filme também procura inventar uma forma capaz de organizar a experiência coletiva daquele trauma. Nela, imbricam-se o documento e a imaginação, a evocação do desastre passado e a meditação sobre o que fazer dele no presente.

Uma obra artística com uma tal ambição e uma tal envergadura convida a uma infinidade de abordagens, de angulações das mais diversas, algumas das quais propostas neste dossiê, do ponto de vista da dimensão literária do filme, da contribuição fundamental de Marguerite Duras para a sua construção, da relação inovadora entre a imagem e o som, do seu modo inventivo de enfrentar os desastres da guerra, e assim por diante.

\footnotetext{
${ }^{1}$ Muriel (1963) evocaria em sua ficção a tortura praticada pelos soldados franceses na Guerra da Argélia, e seu episódio "Claude Ridder" para o filme coletivo Loin du Vietnam (1967) discutiria a agressão americana ao Vietnã nos anos de 1960 e algumas de suas congêneres menos lembradas. 2 Publicado pela Gallimard em 1960, um ano após o lançamento do filme, o texto de Duras ganhou autonomia em relação ao filme, e pode ser examinado como uma peça literária em si mesma. Para informações de contexto sobre a gênese do projeto inteiro (texto e filme), ver DURAS (1997, esp. p. 530-1, 534 e 545) e LEUTRAT (1994, p. 31-7).
} 
No texto que segue, volto a um caso da recepção crítica do filme no Brasil que esperava exame mais aprofundado. Como se sabe, Hiroshima foi um dos longas-metragens de maior, mais variada e mais qualificada fortuna crítica do segundo pós-guerra europeu, desde seu lançamento em 1959, que suscitou uma reação apaixonada na crítica quase inteira. A exemplo daquela produzida em vários outros países, sua fortuna crítica brasileira também foi abundante e variada, como já mostrou e discutiu Alessandra Brum em sua preciosa Tese de Doutorado, Hiroshima mon amour e a recepção da crítica no Brasil (2009), que examina os textos consagrados ao filme, no calor da hora, por 17 dos mais importantes críticos brasileiros então atuantes.

Minha discussão consistirá numa nota de pé de página à contribuição durável de Alessandra, cuja opção pelo panorama em sua pesquisa de fôlego resultou num mapa geral da recepção crítica do filme no Brasil, mas a impediu de aprofundar a discussão da abordagem de alguns dos críticos escolhidos. Reabrindo o dossiê e reexaminando com mais detalhe o caso particular da recepção de Hiroshima por Glauber Rocha, meu propósito aqui é fornecer um exame mais completo da sua relação com o filme e seu diretor, ampliando seu arco temporal e o conjunto dos seus textos a discutir ${ }^{3}$. Nas três seções seguintes, apontarei um movimento, perceptível nos textos, de um entusiasmo inicial de Glauber (expresso em dois artigos inteiramente consagrados a ele) a um afastamento progressivo, que culmina na curiosa ausência de tais artigos do sumário do Século do cinema, seu principal livro sobre o cinema mundial.

\section{Impacto inicial (com oscilações)}

Sediado em Salvador, atuante na imprensa baiana, mas já colaborando com o Suplemento Dominical do Jornal do Brasil, Glauber assistiu ao filme pela primeira vez entre o fim de setembro e meados de outubro de 1960, depois de ter se referido a ele, sem tê-lo visto, em pelo menos 4 artigos de junho a outubro daquele ano, balizado por ecos dos debates que ele suscitou em outras capitais brasileiras ${ }^{4}$ e por textos publicados sobre ele por seus colegas de outros estados. Desde este momento, seus juízos sobre o filme parecem inflamados, oscilando, porém, entre o elogio forte à sua forma (ou à sua montagem em particular) e a

\footnotetext{
${ }^{3}$ A relação de Glauber com o filme vai muito além do que Alessandra explorou em seu precioso estudo (cf. BRUM, 2009, especialmente p. 126-30), cujo valor não diminui em nada diante dos aprofundamentos e das eventuais retificações sugeridos aqui neste caso particular.

${ }^{4}$ Glauber recebe em 1-8-1960 carta de Nelson Pereira dos Santos com um longo parágrafo sobre o filme, que estaria suscitando polêmica no Rio, mas cuja importância e cujas contribuições formais Nelson salienta com vivo entusiasmo, em termos que provavelmente informaram a leitura posterior do amigo baiano (cf. ROCHA, 1997, p. 121-2). Seria interessante examinar de perto quais textos balizaram num primeiro momento a visão de Hiroshima por Glauber (de Paulo Emilio Salles Gomes? José Lino Grünewald? Moniz Vianna?), mas tal exame exigiria um outro estudo, para o qual a tese de Alessandra Brum seria um ponto de partida incontornável.
} 
crítica à sua dimensão literária. Assim, Hiroshima teria integrado elementos da teoria da montagem de Eisenstein, ${ }^{5}$ e sua forma traria "avanços geniais e reformistas"6, quiçá "uma revolução". ${ }^{7}$ Mas os diálogos de Marguerite Duras, "da pior literatura, segundo se comenta", "estrangulam o espectador pela má literatura que possuem" ${ }^{8}$

Em 2-3/10/1960, semanas

antes do seu primeiro texto consagrado ao filme, o Diário de Notícias publica, em Salvador, sem assinatura a nota "O Filme novo: HIROSHIMA" [Fig. 1], republicada quase na íntegra em 21-22/5/1961, sob o título "A obra-prima da Nouvelle Vague" [Fig. 2], novamente sem indicação de autoria, na mesma página em que aparece o segundo artigo de Glauber (ao qual voltarei), este sim assinado com suas iniciais G.R. Embora tenha sido atribuída a Glauber duas vezes em trabalhos recentes, ${ }^{9}$ tudo leva a crer (aí incluídos o estilo e a abordagem pouco glauberianos), com a maior plausibilidade, que aquela nota não é de Glauber, que não a assina em nenhuma das duas versões (a segunda estampada ao lado de um texto assinado), mas da redação do jornal, e provavelmente de Hamilton

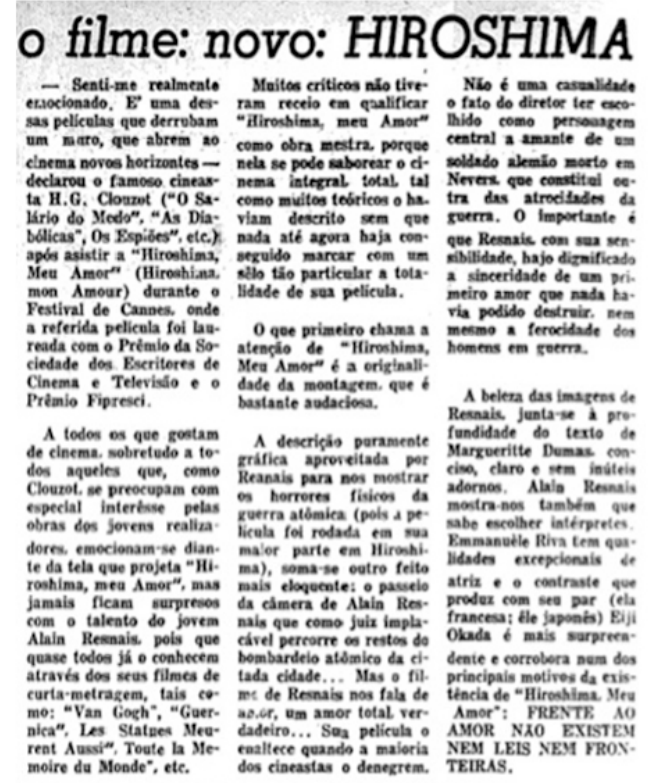

Figura 1. "O Filme novo: HIROSHIMA". Diário de Notícias, 2-3/10/1960, $3^{\circ}$ Caderno, p. 2.

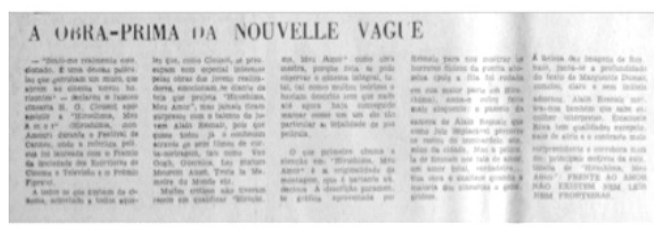

Figura 2. "A obra-prima da Nouvelle Vague". Diário de Noticias, 21-22/5/1961, 3 Caderno, p. 8.

\footnotetext{
${ }^{5}$ Mais que isso, o Resnais de Hiroshima teria sido, como sugere Glauber num ensaio programático sobre Eisenstein, o único cineasta moderno a aproveitar o fundamento de sua teoria dialética da montagem, segundo a qual um fotograma (Tese) só ganharia seu sentido (sua síntese) no choque com outro fotograma oposto (antítese) (cf. ROCHA, [1960a] 2019, p. 175).

6 "O cinema entrou na crise da forma e, salvo os avanços geniais e reformistas como Hiroshima mon amour, de Alain Resnais, não temos outro caminho senão buscar a humanidade como fundamento do filme". (ROCHA, [1960d] 2006a, p. 133)

7 "Ainda não vi Hiroshima, mas já sei, por exemplo, que existem os diálogos de Marguerite Duras - da pior literatura, segundo se comenta. Mesmo que Hiroshima seja uma revolução, acho que o cinema precisa ser repensado" (ROCHA, [1960c] 2019, p. 194).

8 "A nouvelle vague é um movimento de juventude que eu, como jovem, detesto. Imita mal o antigo, não tem coragem moral de romper com a forma antiga do filme e faz má literatura. Inclusive em Hiroshima, meu amor, onde os diálogos de Marguerite Duras estrangulam o espectador pela má literatura que possuem" (ROCHA, [1960b] 2019, p. 154).

${ }^{9}$ No livro proveitoso (mas nem sempre cuidadoso) de BORGES, CAMPOS E AISENGART, além de aparecer com a data trocada com a de outro texto de autoria inequívoca de Glauber, esta nota que ele nunca assinou lhe é atribuída sem nenhuma cláusula de reserva (2008, p. 33). Corrigindo o equívoco da datação, BRUM continua, porém, endossando sem mais tal atribuição duvidosa (2009, p. 126-7).
} 
Correia, crítico e jornalista responsável pela sua editoria de cinema.

No seu primeiro texto sobre o filme [Fig. 3], intitulado "Primeira visão de Hiroshima" (Diário de Notícias, 23-24/10/1960) e dividido em 5 seções, Glauber conjuga uma postura de humildade crítica diante do filme (cujo impacto exigiria, pelo menos de início, a suspensão provisória do juízo) e um elogio entusiástico às suas qualidades, que ele não se priva de fazer.



PRIMEIRA VISÃO DE HIROSHIMA Glauber Rocha
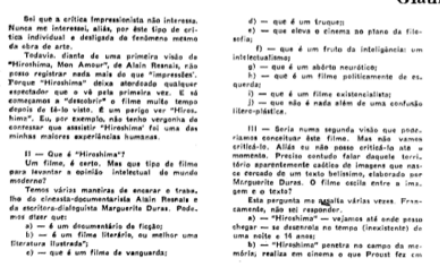

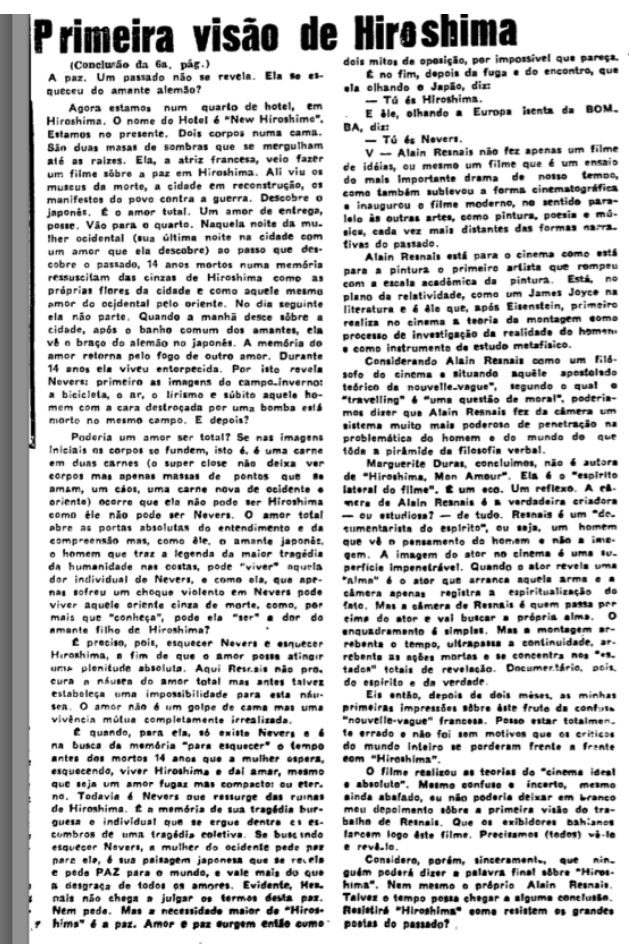

Figura 3. "Primeira visão de Hiroshima". Diário de Notícias, 23-24/10/1960, Suplemento Artes e Letras, $3^{\circ}$ Caderno, p. 6 e 2.

Esta coexistência de dois gestos quase incompatíveis de suspender o juízo (incomum em seus textos da época) e de proferi-lo com ênfase, sem economia de superlativos, aparece logo na primeira seção do artigo, antes de reaparecer na terceira:

Todavia, diante de uma primeira visão de Hiroshima, mon amour, de Alain Resnais, não posso registrar nada mais do que "impressões". Porque Hiroshima deixa atordoado qualquer espectador que o vê pela primeira vez. E só começamos a "descobrir" o filme muito tempo depois de tê-lo visto. É um perigo ver Hiroshima. Eu, por exemplo, não tenho vergonha de confessar que assistir Hiroshima foi uma das minhas maiores experiências humanas. [...] Seria numa segunda visão que poderíamos conceituar este filme. Mas não vamos criticá-lo. Aliás, eu não posso criticá-lo até o momento. Preciso contudo falar daquele território aparentemente caótico de imagens que nasce cercado de um texto belíssimo, elaborado por Marguerite Duras. O filme oscila entre a imagem e o texto? Esta pergunta me 
assalta várias vezes. Francamente, não sei responder. (ROCHA, [1960e] 2019, p. 155)

Na continuação do texto reaparecem cláusulas de prudência, como "vejamos até onde posso chegar", "posso estar totalmente errado", "mesmo confuso e incerto" e "ninguém poderá dizer a palavra final sobre Hiroshima. Nem mesmo o próprio Alain Resnais. Talvez o tempo possa chegar a alguma conclusão". Mas elas não impedem Glauber de avançar juízos enfáticos e afirmar a excelência do filme, caracterizado preliminarmente na seção II em dez breves fórmulas (algumas valorizantes, outras pejorativas), das quais o texto parece explorar nas seções seguintes as ressonâncias de pelo menos três, abordando o longa como "um filme literário, ou melhor, uma "literatura ilustrada'", como "um filme de vanguarda" e um filme "que eleva o cinema ao plano da filosofia". Recomposta a intriga de Hiroshima na seção IV, Glauber julga que

Alain Resnais não fez apenas um filme de ideias, ou mesmo um
filme que é um ensaio do mais importante drama de nosso
tempo, como também sublevou a forma cinematográfica e
inaugurou o filme moderno, no sentido paralelo às outras artes,
como pintura, poesia e música, cada vez mais distantes das
formas narrativas do passado. Alain Resnais está para o cinema
assim como está para a pintura o primeiro artista que rompeu
com a escola acadêmica da pintura. Está, no plano da
relatividade, como um James Joyce na literatura, é é ele que, após
Eisenstein, primeiro realiza no cinema a teoria da montagem
como processo de investigação da realidade do homem e como
instrumento de estudo metafísico. (ROCHA, [1960e] 2019, p. 159)

Depois de comparar a novidade do filme de Resnais com aquelas introduzidas por inovadores de outras artes (Joyce na literatura, Eisenstein no cinema), Glauber estende a analogia à filosofia, e fala de Resnais como "um filósofo do cinema", que "fez da câmera um sistema mais poderoso de penetração na problemática do homem e do mundo do que toda a pirâmide da filosofia verbal". O filme constituiria assim uma operação de conhecimento filosófico do mundo, mais poderoso até do que a filosofia em sentido estrito.

Tal operação resultaria menos do texto de Duras (que não seria a verdadeira autora do filme, mas seu "espírito lateral") do que da direção de Resnais: "A câmera de Resnais é a verdadeira criadora - ou estudiosa? - de tudo. Resnais é um 'documentarista do espírito', ou seja, um homem que vê o pensamento do homem e não a imagem. [...] O enquadramento é simples. Mas a montagem arrebenta o tempo, ultrapassa a continuidade, arrebenta as ações mortas e se concentra nos 'estados' totais de revelação. Documentário, pois, do espírito e da verdade" (p. 160). 
Por tudo isso, Glauber se permite, de modo novamente enfático, concluir que o filme "realizou as teorias do 'cinema ideal e absoluto'". Para quem acenou de início com uma suspensão do juízo, Glauber acaba deixando afirmações entusiásticas neste primeiro texto: o filme realizaria as teorias do cinema ideal e absoluto, inovaria como já haviam feito Eisenstein no cinema e Joyce na literatura, faria com a câmera filosofia mais penetrante que a filosofia escrita, inauguraria o cinema moderno. Os textos seguintes, ainda que elogiosos, parecem, porém, mais comedidos.

Em seu segundo artigo consagrado ao filme, "Hiroshima: poema verbo-visual (polêmica)", publicado também no Diário de Notícias (2122/5/1961) [Fig. 4],10 Glauber começa dizendo que "esta nota não pretende analisar Hiroshima, meu amor", cujo caráter polêmico (mote da página do jornal) ele salienta de início.

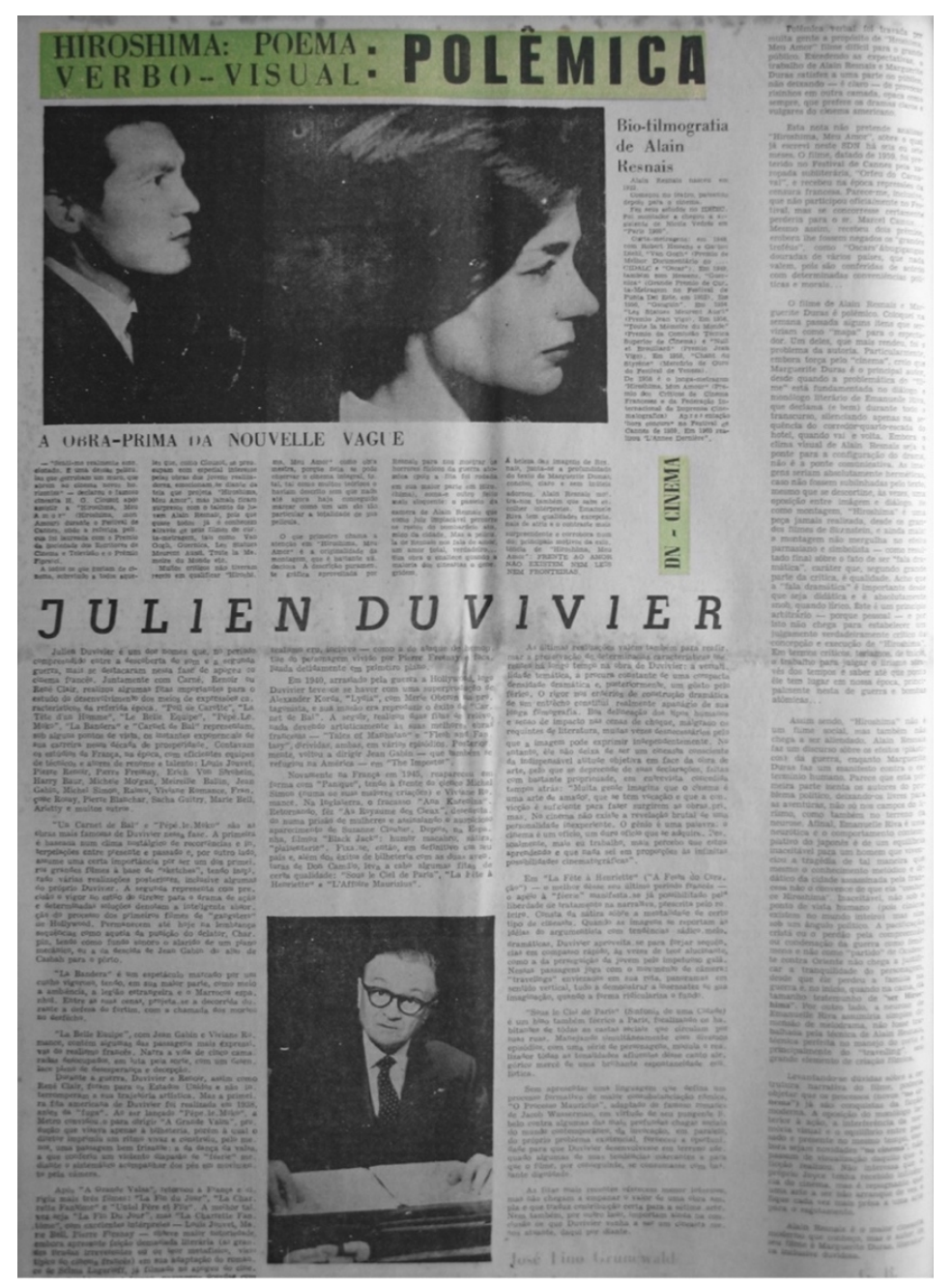

Figura 4. "Hiroshima poema verbo-visual (polêmica)" Diário de Noticias, 21 e 25/5/1961, Suplemento Artes e Letras, $3^{\circ}$ Caderno, p. 8). Assinado em verde pelas iniciais G.R., o texto de Glauber é o da coluna lateral à direita.

10 Curiosamente, este segundo artigo de Glauber consagrado a Hiroshima passou desapercebido tanto a BORGES, CAMPOS E AISENGART (2008) quanto a BRUM (2009), o que limitou seus respectivos dossiês. 
Depois, o crítico baiano reconsidera sua posição sobre a autoria principal do filme, que ele atribuíra no artigo anterior a Resnais, mas que agora atribui a Duras:

\begin{abstract}
Particularmente, embora torça pelo "cinema", creio que Marguerite Duras é o principal autor, desde quando a problemática do "filme" está fundamentada no diálogo e no monólogo literário de Emanuelle Riva, que declama (e bem) durante todo o transcurso, silenciando apenas na sequência do corredor-quarto-escada do hotel, quando vai e volta. Embora o clima visual de Alain Resnais seja a ponte para a configuração do drama, não é a ponte comunicativa. As imagens seriam absolutamente herméticas, caso não fossem sublinhadas pelo texto, mesmo que se descortine, às vezes, uma oposição entre imagem e diálogo. (ROCHA, [1961c] 2019, p. 162)
\end{abstract}

Inversão completa da sua avaliação, portanto, que ele reitera na conclusão do texto, sob a forma de um paradoxo: "Alain Resnais é o maior cineasta moderno que conheço, mas o autor de seu filme é Marguerite Duras, literatura inclusive duvidosa". Aqui se inverte a própria avaliação do texto de Duras, qualificado de "belíssimo" no artigo anterior, e agora chamado de literatura duvidosa. Essa reserva em relação ao texto dá a tônica deste novo artigo, que continua salientando qualidades formais do filme (montagem, técnica visual, uso do travelling), mas sugere limites em seu uso lírico da "fala dramática", no comportamento neurótico das personagens e mesmo na sua estrutura narrativa.

Sua montagem traria contribuição inédita "desde os grandes filmes de Eisenstein", mas o lirismo de sua "fala dramática" neutralizaria sua dimensão política, ainda que não chegasse a torná-lo um filme "alienado". A construção dos dois personagens principais também revelaria problemas, a do homem pela tranquilidade injustificável que ele apresenta diante da tragédia da bomba, e a da mulher pela neurose, que "assumiria simples dimensão de melodrama, não fosse trabalhada pela técnica de Alain Resnais, técnica perfeita no manejo do corte e principalmente do travelling, seu grande elemento de criação fílmica". Até mesmo à celebrada estrutura narrativa do filme "se poderia objetar que os processos (novos 'no cinema') já são conquista da ficção moderna". Ela se limitaria a transpor para o cinema conquistas da literatura moderna, sem libertar o cinema do modelo literário:

A oposição do monólogo interior à ação, a interferência da memória visual e o equilíbrio entre passado e presente no mesmo tempo, embora sejam novidades "no cinema", não passam de visualização daquilo que a ficção realizou. Não interessa que o próprio Joyce tenha recebido influência do cinema, mas é repugnante que uma arte a ser não arranque de vez e fique cada 
vez mais presa a uma arte para o esgotamento. (ROCHA, [1961c] 2019, p. 163-4)

Abrupto, menos feliz na escrita e menos claro na argumentação, este segundo artigo patenteia em todo caso um certo refluxo do entusiasmo inicial de Glauber com o filme, que ele continua elogiando, mas que agora lhe inspira também algumas reservas.

\section{Nuances e comparações desfavoráveis}

Sem prejuízo do respeito que Glauber continua devotando a Resnais e seu filme, tais reservas aparecem também nas menções a eles presentes em seus textos paralelos e posteriores, ao longo da década de 1960, dedicados a outros objetos. Nestes textos, Glauber diz acompanhar Resnais com atenção, ${ }^{11}$ e continua a mencioná-lo como se o considerasse um dos maiores cineastas franceses modernos ${ }^{12}$ ou um dos mais importantes representantes do cinema europeu de autor..$^{13}$ De resto, nesta década como na seguinte, não é raro vê-lo invocando o colega francês aqui e ali ao discutir outros cineastas ${ }^{14}$, aí incluídos os brasileiros, como Joaquim Pedro de Andrade, David Neves e até mesmo Humberto Mauro. ${ }^{15}$

\footnotetext{
11 "Dois cineastas franceses que acompanho com atenção: Resnais e Jacques Rivette" (ROCHA, [1969b] 2004, p. 153).

${ }^{12}$ Frequentemente ao lado de Godard e Truffaut (cf. ROCHA, [1963b] 2006a, p. 173; [1966a] 2006a, p. 186; [1969a] 2004, p. 174; 1997, p. 194).

${ }^{13}$ Em declarações que o citam num par com Antonioni ("Acho que a grande importância de Antonioni e Resnais são as imagens finais do velho mundo - imagens abstratas, homens sem alma, gestos liquidados, espaços que se movem e se perdem num tempo eternamente em circuito", ROCHA, [1962b] 2006a, p. 253; "daqui a mais dois anos, quando os boçais estiverem no profissionalismo, já estaremos fazendo filmes tão importantes como hoje fazem na França Resnais e Antonioni", (ROCHA, [1963a] 1997, p. 194), ou em enumerações maiores que também incluem Bergman, Buñuel, Fellini, os franceses etc. (cf. ROCHA, 1963c, p. 35 e 40; [1964a] 2004, p. 61; [1964b] 2019, p. 144; [1977] 2006a, p. 273).

${ }_{14}$ Assim, o tratamento do tempo no cinema argentino é criticado como "pré-resnaisiano" (cf. ROCHA, [1967b] 2004, p. 105), e seus devaneios estetizantes ocultariam, "nas imitações de Bergman, Antonioni e Resnais, o drama do povo, o drama dos pampas, o drama dos Martins Hierros de la vyda cujo representante era Che..." (ROCHA, [1978] 2004, p. 368); o uso por Lang em $M$ do som de uma imagem em cima de outra imagem sem som anteciparia Resnais (cf. ROCHA, [1968b] 2006a, p. 47); a montagem de um filme chamado Consciências Compradas de um certo Timothy Anger lembraria indiretamente O ano passado em Marienbad (cf. ROCHA, [1970] 2006a, p. 147).

${ }^{15} \mathrm{O}$ estilo de $O$ padre e a moça (Joaquim Pedro, 1965) o inscreveria numa linhagem dos grandes cineastas intimistas, dentre os quais Dreyer, Bresson, Resnais e Bergman (ROCHA, [1966] 2004, p. 82), que segundo um texto posterior ajudariam Joaquim a filtrar sua identificação a Nelson Pereira dos Santos (ROCHA, [1980b] 2004, p. 445). Ecos de Resnais e seu Hiroshima estariam presentes também em Memórias de Helena (1969), primeiro longa de David Neves (ROCHA, [1980a] 2004, p. 407). Quanto a Mauro, a montagem de Ganga Bruta prenunciaria, ou faria o espectador moderno pensar no "ritmo especulativo de um Resnais" (ROCHA, 1963c, p. 53).
} 
Mas seus elogios se alternam com considerações críticas, ${ }^{16}$ e vêm frequentemente temperados por alguma ponderação, como neste longo trecho de "América Nuestra" (1969), exemplar destas oscilações, pois cheio de observações conflitantes sobre seus filmes:

Pode-se dizer que a nouvelle vague criou uma estética burguesa por excelência. Isto se confundiu com o chamado cinema de autor que se confunde por sua vez com ineficácia. Os únicos filmes desta escola que fizeram sucesso foram por motivos sexuais - e outros como Hiroshima e La guerre est finie [A guerra acabou] de Resnais, ou alguns de Truffaut - por algumas inegáveis qualidades de ruptura. A ruptura de Resnais é préjoyceana. O que caracteriza esta extraordinária capacidade do francês atual para criticar sua incapacidade criativa. Resnais desarticulou o tempo sem articular a dialética. Seu cinema poderia ser dialético se não fosse literário - quero dizer burguês - com o clássico problema da consciência. E com dados moralistas esnobes e infantis como as cenas de amor de La guerre est finie, a sacanagem "artística" exemplar. Uma coisa fraca de Resnais: seus atores. Mas é um documentarista genial e foi um revitalizador do travelling no cinema. Nuit et brouillard [Noite $e$ nevoeiro] é um filme de estrutura dialética e Toute la mémoire du monde, um poema (antididático) de grande beleza. Como os instantes iniciais de Hiroshima. Mas como é triste seu episódio em Loin du Vietnam. O ano passado em Marienbad [L'année dernière à Marienbad] é um ensaio de obra-prima expressionista, literário, subjugado a um neoliterato como Robbe-Grillet. Mas é um filme fascinante, embora sua aparente modernidade esconda profundo academicismo. Se Resnais fosse alemão, Marienbad seria uma obra-prima. Há travellings geniais! Eisenstein amaria Marienbad. (ROCHA, [1969c] 2004, p. 168-9)

Num mesmo trecho, as "inegáveis qualidades de ruptura" de Hiroshima são qualificadas, porém, de "pré-joyceanas". Sua desarticulação do tempo aparece como incapaz de articular a dialética por seu caráter literário ou burguês, preso ao problema da consciência. Os elogios ao seu documentarismo genial, à sua revitalização do travelling, à estrutura dialética de Nuit et brouillard, à beleza de Toute la mémoire du monde (1956) e ao início de Hiroshima convivem com as duras críticas a La guerre est finie (1966), à fraqueza dos atores, ao seu episódio de Loin du Vietnam (1967). Para coroar o conjunto de considerações pendulares, cada frase sobre Marienbad conjuga elogios e críticas.

\footnotetext{
${ }^{16}$ Como no texto em que Glauber inclui Hiroshima no rol de "grandes peças literárias ilustradas na imagem" que não merecem, porém, sua adesão: "Espero que não consideremos bons filmes as boas faturas comerciais do cinema: o melhor Hitchcock ou grandes peças literárias ilustradas na imagem, como é o caso de Fellini e Bergman (cuja própria literatura, pelo caráter híbrido, é duvidosa) e, até certo ponto, Hiroshima mon amour. Quando digo bons, não estou negando estes filmes, mas apenas perguntando se são realmente filmes" (ROCHA, [1961b] 2004, p. 47-8).
} 
Se este convívio de avaliações contrastantes tende a matizar o entusiasmo inicial de Glauber por Hiroshima e seu diretor, também o matizam os vários textos nos quais Glauber estabelece alguma forma de comparação entre Resnais e outros cineastas, que parecem levar vantagem. A começar por um artigo de março de 1961 sobre um filme americano obscuro, Studs Lonigan (Irving Lerner, 1960), do qual Glauber faz um elogio ditirâmbico, comparando-o a filmes de Welles, Kubrick e a Hiroshima:

Eis o maior filme americano, a obra que ultrapassou Orson Welles e Stanley Kubrick e que se integra ao lado de Hiroshima, meu amor, de Alain Resnais. Um filme genial, um filme moderno, revolucionário, que está para o cinema como Joyce para a literatura: Studs Lonigan - produção de classe B, escrita e produzida pelo veterano e irregular Philip Yordan e dirigido por Irving Lerner. Confesso que desde Eisenstein e Jean Vigo somente The Killing e Killer's Kiss, de Kubrick, e mais tarde Hiroshima, meu amor, foram filmes que me impressionaram [tanto] como fenômeno estético. (ROCHA, [1961a, p. 4] 2006a, p. 133)

Além de revelar o entusiasmo pelo filme de Lerner, a comparação também coloca Hiroshima num alto patamar de admiração do crítico. Mas ao detalhá-la mais adiante, Glauber sugere que o trabalho com o monólogo interior, a montagem e o tempo são mais audazes no filme de Lerner do que no de Resnais:

O monólogo interior, teorizado por Eisenstein, até então recurso narrativo da literatura, passa, nas mãos de Irving Lerner, a ser elemento realizado muito mais do que em mãos de Resnais. Enquanto o autor de Hiroshima, meu amor retrocede no tempo - e aí tem um handicap para interromper a narrativa, Irving Lerner usa processo próximo de William Faulkner: narra simultaneamente quatro elementos: duas ações - a de Studs excitado e o da professora normal; e "duas consciências" - a professora sob a memória perturbada de Studs. A montagem é simultânea e não paralela. E a fusão de som e imagem também, todas conjugadas ao mesmo tempo. Assim, no cinema, a consciência humana é trazida até a imagem. Alain Resnais trouxe apenas a memória. (ROCHA, [1961a] 2006a, p. 136)

Lerner teria realizado melhor do que o Resnais de Hiroshima o monólogo interior, teria ido além da montagem paralela de Resnais numa montagem simultânea, e teria alargado sua representação da memória por uma representação da consciência.

Em comparações posteriores entre Resnais e outros cineastas de sua admiração (Visconti, Buñuel, Straub \& Huillet, Fellini), Glauber parece revelar sua preferência por eles. Ao defender, por exemplo, ainda em 1961, Rocco e seus irmãos (Visconti, 1959), Glauber contrapõe a força de seu 
discurso aparentemente baseado numa forma convencional à novidade explosiva do filme de Resnais, cuja modernidade não lhe seria superior, e cujos limites ele procura apontar: ${ }^{17}$

Rocco - por mais que seja considerado apenas "obra-prima do cinema tradicional" - é tão moderno em seu caráter estilístico quanto Hiroshima mon amour - que, embora surja como um "novo", não passa - caso seja analisado estruturalmente - de um filme "novo no cinema", mas não "novo para o cinema", ou seja, os processos narrativos de Resnais são roman nouveau acrescentados de capítulos da técnica atemporal de Faulkner como ainda sustentados pela teoria eisensteiniana do monólogo cinematográfico, exposto em Film Form, quando o mestre russo estudava a adaptação de Ulysses de Joyce. (ROCHA, [1961d] 2006a, p. 229)

O curioso é que Glauber saliente as limitações da novidade do processo narrativo de Hiroshima reduzindo-os a uma transposição para o cinema de processos herdados da literatura - Nouveau roman, Faulkner ou da teoria do monólogo interior de Eisenstein, ela mesma remetida de certa forma ao seu estudo dos procedimentos literários de Joyce. Assim, embora a comparação com manifestações literárias e cinematográficas de envergadura tendam a valorizar Resnais, ao mesmo tempo parecem sugerir que ele não foi além de uma mera transposição destas contribuições anteriores para o campo do cinema, para cujo desenvolvimento interno ele não teria contribuído significativamente. Esta ideia fica ainda mais clara logo adiante, quando Hiroshima é comparado ao romance de Proust:

Quando Resnais rompeu com o tempo cinematográfico vigente,
estava apenas fazendo o que o romance já fez desde Proust: e
como problema colocado - salientando-se memória \&
esquecimento - ainda estamos em Proust que transcende o ciclo
do tempo perdido à existência de Hiroshima. [...] O discurso
revolucionário está no romance dos grandes autores -
Dostoiévski, Dickens, Stendhal, Proust, Joyce e Faulkner (para
citar meia dúzia representativa) e no cinema só começa a existir
em Hiroshima, que é uma consequência da experiência ficcional e
do próprio desespero desta forma narrativa, aniquilada não só
pelos destinos a que foi levada pela liberdade da palavra como
também pela evidência da força comunicativa do cinema, nos
planos do "social" e da "percepção". Mas se Hiroshima vale
também porque é um filme que traz para o cinema o novo
processo narrativo - um método de conhecimento humano -
Rocco vale porque desencadeia o conhecimento na linguagem
aparentemente tradicional - destruindo ao mesmo tempo a linha
comportada da velha cronologia cinematográfica, impondo a

17 Ismail Xavier (cf. 2006, p. 19-20) comenta, com a lucidez habitual, as razões do privilégio concedido por Glauber ao filme de Visconti sobre o de Resnais. 
linha sinuosa do romance à realização da obra. (ROCHA, [1961d] 2006a, p. 229-30)

O prejuízo de Resnais na comparação fica mais claro no caso de Buñuel. Numa entrevista a Diva Múcio Teixeira de 29/7/1962, respondendo a uma pergunta sobre o cinema europeu, Glauber contrapõe Buñuel a Antonioni e Resnais, sinalizando claramente sua preferência pelo cineasta espanhol:

\begin{abstract}
Para mim só existe um nome no cinema de hoje ao lado de Visconti: Luis Buñuel. Nazarin, Viridiana e Ángel exterminador são os filmes mais importantes da história do cinema moderno. O delírio em torno de Alain Resnais e Antonioni é violento, justificável. Não se fala muito em Buñuel, justamente porque é mais profundo e menos sensacionalista. Os críticos discutem o tempo todo Resnais e Antonioni. A crítica da França e da Itália também. Mas ambos buscam problemas que Buñuel já resolveu há muito. [...] Não sendo um moralista e violentando a sociedade com um anarquismo cada vez mais forte, Buñuel não se perde na automutilação de Antonioni e Resnais, ambos a caminho do abstracionismo. [...] Creio que o cinema anda mal porque o cineasta quer ser metteur-en-scène. Cinema é fundamentalmente pensamento. Se o autor é um decadente burguês diletante faz como Alain Resnais. Se é um desesperado e cético, faz como Antonioni. Se é um anarquista viril e uma esquerda eterna, faz como Buñuel. (ROCHA, 1962a, p. 4)
\end{abstract}

Esta entrevista marca com clareza uma decisão crítica de Glauber em favor de Buñuel, que tem de resto um caráter não só estético como também político. Ela atravessará a década de 1960 sem abalos maiores, como atesta uma carta a Jean-Claude Bernardet (Paris, 12/7/1967). Nela, Glauber volta a exprimir seu entusiasmo com o cineasta espanhol (assim como sua estima constante por Godard), ao mesmo tempo em que tempera seu respeito de outrora a Resnais e outros com alguma reserva: "Não vi nada de bom, a não ser o estertor final do velho cinema de Bergman, Antonioni, Resnais, Visconti. A tentativa que eles fazem pra ser modernos é suicida" (ROCHA, [1967a] 1997, p.281). Em compensação, "vi tudo de Buñuel. Quando a gente vê o conjunto de Chien andalou a Belle de Jour é que [vê] que ele é o melhor mesmo, o único imperturbável" (Idem, ib.).

Isto volta a ocorrer um ano depois, no artigo "O Novo cinema no mundo". Ali, ao discutir a figura estilística do "plano integral", Glauber volta a contrapor Buñuel e outros cineastas (mais capazes de empreendêlo) a um grupo incluindo Resnais (que não teria conseguido alcançá-lo plenamente). Assim como Antonioni, Bergman e Visconti, Resnais estaria aquém dos resultados obtidos nesta direção por Buñuel, Welles e Rossellini: 
A conquista da nova linguagem está no início, mas o estágio da descoberta da realidade pela câmera na mão já se supera pelo estágio da análise da realidade pelo plano integral. É um território misterioso no qual nem Antonioni, nem Bergman, nem Visconti, nem Resnais ainda penetraram, se bem que se tenham manifestado neste sentido. Os únicos cineastas tradicionais (ou modernos) capazes de exercer este cinema são Buñuel, Welles e Rossellini, poetas cuja influência se faz cada vez mais sentir no cinema moderno, não pelos seus caracteres exóticos, mas sim pelo insólito permanente de suas obras. Buñuel, antes de Rossellini, em Un chien andalou, já fazia cinema moderno. Liberdade de criação à margem da ditadura industrial. (ROCHA, [1968a] 2006a, p. 345)

Mais adiante, ao fazer o elogio de Jean-Marie Straub, Glauber retoma a questão do plano integral, e contrapõe o seu modo de explorar o tempo ao de Resnais, que parece sair perdendo na comparação:

O plano integral, em Straub, atinge sua plenitude. O filme obedece à técnica de um plano para cada ação ou uma ideia para cada plano. É uma sucessão de planos diretos frontais, em geral fixos, que se unem por rápidas fusões em negro. O diálogo é dito friamente, sem adjetivos, como um recitativo coral. Os atores pouco se movem. O tempo é livre, o filme se passa no presente e no passado. Corta do passado para o presente e vice-versa sem os artifícios de Resnais ou técnicas clássicas de flashbacks. Tudo se dá na tela. O diálogo, o texto, os ruídos, a rara música, agem simultaneamente. O tempo (escravizante noção de tempo) é abolido, o filme É. (ROCHA, [1968a] 2006a, p. 350)

Alguns anos depois, num texto notável de homenagem a Fellini, Glauber salienta a sua liberdade e a sua autonomia maiores do que a de outros "cineautores", Resnais incluído: "Casanova é sucesso moderado de Fellini, num mercado de Cinautores, dominado por Bergman, Antonioni, Buñuel, Resnais etc., - sendo que Fellini é o mais caro, o mais livre e o menos comprometido com as regras do jogo" (ROCHA, [1977] 2006a, p. 273).

Guardadas as suas diferenças, todos estes trechos sugerem, cada um a seu modo e a partir da sua questão específica, a preferência de Glauber por outros cineastas dos quais Resnais aparece como um comparante desfavorecido. Naturalmente, a simples inclusão do seu nome num conjunto de cineastas que contam (e sustentam, portanto, comparação) indica sempre a consideração que ele continua merecendo de Glauber, mas seu lugar nas comparações deixa claro que a adesão maior do brasileiro tem sempre outro endereço. 


\section{Eclipse}

A partir dos anos de 1970, Resnais e Hiroshima praticamente somem dos textos e declarações de Glauber, que parece perder o interesse pelo trabalho do colega francês, em benefício de outros cineastas com os quais sentia afinidades maiores - alguns já objetos de textos seus anteriores (Rossellini, Pasolini, Buñuel, Godard, Straub \& Huillet), outros transformados em amigos ou invocados em entrevistas e declarações (Bertolucci, Carmelo Bene, Miklos Jancso, Robert Kramer, Gutierrez Alea etc.). ${ }^{18}$

Isto talvez decorra da sua distância em relação aos filmes de Resnais do período - não me lembro, por exemplo, de declarações suas sobre filmes de Resnais posteriores a La guerre est finie e ao seu sketch para Loin du Vietnam - dos quais ele já não gostava ${ }^{19}$. Mas talvez se deva também à consolidação do seu próprio projeto de cinema a partir de Deus e o diabo na terra do sol20, que raramente buscou explorar a região da interioridade psíquica, ou o tempo interno da consciência. Com a exceção de Terra em transe, ${ }^{21}$ eventuais ecos de Resnais são raros em seus filmes, que não investem na interioridade, no flashback, na exploração das camadas de tempo, e parecem portanto ter pouco a integrar do programa geral de cinema do colega francês, bem como da poética de Hiroshima.

O refluxo do entusiasmo inicial de Glauber com Hiroshima culmina na sua decisão de não incluir seus dois artigos sobre o filme no sumário do Século do cinema, ${ }^{22}$ antologia de seus textos sobre o cinema mundial que ele

\footnotetext{
18 Num artigo de 1980, uma afirmação provocativa de Glauber desenha um cânone ainda mais renovado: "à exceção de Godard, dos argentinos Fernando Solanas e Fernando Birri, do yankee Robert Kramer, dos alemães Werner Schroeter e Hans Jürgen Syberberg, do cinema novo Brazyleyro, do soviético Andrey Tarkovsky, do cubano Tomaz Gutiérrez Alea, do espanhol Carlos Saura, do italiano Carmelo Bene e de pouquíssimos outros cineastas, tudo o que se produz hoje no cinema é lixo teatral romanesco" (ROCHA, 1980a, p. 51).

${ }^{19}$ Não cheguei a fazer pesquisa exaustiva nos textos publicados por Glauber no período, e os inéditos aumentariam pesadamente a tarefa. Em todo caso, mais do que examinar a totalidade dos seus escritos, importa aqui assinalar a tendência clara em Glauber de se afastar de Resnais.

${ }^{20}$ Curiosamente, e à diferença dos seus outros exegetas, Walter da Silveira $(1965$, p. 180) sugere que o trabalho com a oralidade em Deus e o diabo se inspira nas experiências sonoras de Resnais em Nuit et brouillard e Hiroshima mon amour, o que me parece pouco convincente, assim como soa estranha uma nota do próprio Glauber segundo a qual ele teria usado, num dos blocos do filme passados em Monte Santo, "os processos de montagem de que dispunha - desde Eisenstein até Resnais" (1965, p. 53, n. 10). Revendo hoje as sequências em questão, à luz do que conhecemos dos filmes de Resnais, fica difícil detectar nelas algum traço da montagem do francês.

${ }^{21}$ Ismail Xavier (2006, p. 19) tem toda a razão em salientar a convergência de Terra em transe com Hiroshima na relação complexa entre imagem e som ou espaço e tempo, e podemos acrescentar a importância em ambos do fluxo de consciência dos protagonistas, mas a meu ver a proximidade se encerra aí. A dramaturgia, o tom e o estilo de Terra em transe parecem distantes de Resnais, mesmo o de La guerre est finie, que tem uma problemática mais estritamente política e um protagonista intelectual dividido entre a política e o amor.

${ }^{22}$ Não é fácil interpretar tal decisão. Seria insuficiente atribuí-la apenas a uma eventual falta de recortes dos dois textos na coleção pessoal de Glauber no momento da sua organização dos originais. De fato, não os encontramos na lista dos seus numerosos artigos publicados que o
} 
preparou antes de morrer, embora não tenha chegado a ver sua publicação, póstuma de dois anos. Dado o forte impacto causado pelo filme no jovem Glauber, soa estranha sua exclusão deste par de textos do sumário final do livro, em cujo panteão o filme poderia figurar ao lado de outras manifestações renovadoras do cinema moderno aos olhos do jovem Glauber. Embora não seja a única estranheza deste sumário, ${ }^{23}$ tal ausência prejudica o livro ao desequilibrar um pouco sua estrutura, privando a seção "Nouvelle Vague" (a mais magra do volume) de um cineasta que fortaleceria seus quadros na comparação com as seções anteriores ("Hollywood" e "Neo-Realismo", mais fortes e variadas), deixando assim o cinema francês mal representado por textos pouco significativos sobre cineastas menores como Jules Dassin e Roger Vadim, indignos de suas discussões sobre Godard e Truffaut. Mutilando também o elenco dos seus elogios de juventude a uma vertente do cinema moderno que, na passagem da década de 1950 para a de 1960, lhe pareceu trazer significativas inovações formais (restaram seus textos sobre Kubrick e Irving Lerner, desacompanhados de seu contraponto francês). Criando enfim o risco de uma visão exagerada de sua admiração por outros cineastas, pela supressão de um objeto que num dado momento dividiu com eles sua atenção e suas apostas críticas.

Seja como for, esta exclusão consuma o eclipse de Hiroshima no itinerário intelectual de Glauber. Acompanhar a curva temporal de suas considerações sobre o filme e seu diretor nos permite redescobrir um amor de sua cinefilia de juventude, formulado em sua declaração tonitruante segundo a qual "assistir Hiroshima foi uma das minhas maiores experiências humanas". Mas permite também perceber como ele foi, com o passar dos anos, se eclipsando por outros amores de maturidade.

\section{Referências bibliográficas}

ANÔNIMO. "O Filme novo: HIROSHIMA". Diário de Notícias. Salvador, 2 e 3 out. 1960, Suplemento Artes e Letras, $3^{\circ}$ Caderno, p. 2.

ANÔNIMO. "A obra-prima da Nouvelle Vague". Diário de Noticias, Salvador, 21 e 22 mai. 1961, Suplemento Artes e Letras, $3^{\circ}$ Caderno, p. 8. ARAÚJO, Mateus. "Sobre a crítica esparsa de Glauber Rocha”. In: ROCHA, Glauber. Crítica esparsa (1957-1965). ARAÚJO, Mateus (org.). Belo

Tempo Glauber vendeu ao MinC e transferiu para a Cinemateca Brasileira já no nosso século, o que faz supor que o cineasta não os tinha ao alcance da mão naquela altura. Mas se quisesse então utilizá-los, não seria difícil localizá-los e copiá-los, com a ajuda de amigos, em acervos do Rio ou de Salvador...

${ }^{23}$ Ao estabelecer com Cyril Béghin uma edição francesa deste livro em 2006, tive ocasião não só de apontar outras estranhezas, como também de corrigir algumas delas (cf. nosso "Avantpropos" em ROCHA, 2006b, p. 10-1, e o sumário daquela edição à p. 331-3). 
Horizonte: Fundação Clóvis Salgado, 2019, p. 10-22.

BRUM, Alessandra. Hiroshima mon amour e a recepção da crítica no Brasil. Campinas: Ed. Unicamp, 2009.

DURAS, Marguerite. Hiroshima mon amour [1960]. In: Duras: Romans, cinéma, théâtre, un parcours 1943-1993. Paris: Quarto Gallimard, 1997, p. 533643.

LEUTRAT, Jean-Louis. Hiroshima mon amour: étude critique. Col. Synopsis. Paris: Nathan, 1994.

LIANDRAT-GUIGUES, Suzanne \& LEUTRAT, Jean-Louis. Alain Resnais: Liaisons secrètes, accords vagabonds. Paris: Cahiers du cinéma, 2006.

ROCHA, Glauber. Conhecimento de S. M. Eisenstein. [1960a]. Diário de Notícias. Salvador, 5 e 6 jun. 1960, $3^{\circ}$ Caderno, Suplemento Artes e Letras, p. 3 (republicado em ROCHA, 2019, p. 172-85).

ROCHA, Glauber. "Elevador (ou alcova): Louis Malle". [1960b]. Diário de Noticias. Salvador, 7 e 8 ago. 1960, $3^{\circ}$ Caderno, Suplemento Artes e Letras, p. 3 (republicado em ROCHA, 2019, p. 150-4).

ROCHA, Glauber. "Cegonhas soviéticas ou tirania das belas-artes". [1960c]. Jornal do Brasil. Rio de Janeiro, 27 set. 1960, Suplemento Dominical, p. 8. (republicado em ROCHA, 2019, p. 186-95).

ROCHA, Glauber. "O preço da ideia" [1960d]. Diário de Notícias. Salvador, 9 e 10 out. 1960, $3^{\circ}$ Caderno, Suplemento Artes e Letras, p. 6 (republicado em ROCHA, 2006a, p. 129-33).

ROCHA, Glauber. "Primeira visão de Hiroshima" [1960e]. Diário de Notícias, 23 e 24 out. 1960, Suplemento Artes e Letras, $3^{\circ}$ Caderno, p. 6 e 2 (republicado em ROCHA, 2019, p. 155-60).

ROCHA, Glauber. "Studs: um filme genial perdido na Bahia (Tupy)" [1961a]. Diário de Notícias. Salvador, 12 e 13 mar. 1961, 2 Caderno, Suplemento Artes e Letras, p. 4 e 6 (republicado sob o título "Um filme genial", em ROCHA, 2006a, p. 133-7).

ROCHA, Glauber. "O processo cinema" [1961b]. Jornal do Brasil. Rio de Janeiro, 6 mai. 1961, Suplemento Dominical, p. 3 (republicado sob o título “O processo cinema 61", em ROCHA, 2004, p. 43-50).

ROCHA, Glauber. "Hiroshima poema verbo-visual (polêmica)" [1961c]. Diário de Noticias. Salvador, 21 e 22 mai. 1961, Suplemento Artes e Letras, $3^{\circ}$ Caderno, p. 8 (republicado em ROCHA, Glauber, 2019, p. 161-4).

ROCHA, Glauber. "Glauber Rocha /Exclusivo para DN. Comenta a última tragédia de Luchino Visconti: Rocco, Abel e Caim" [1961d]. Diário de Notícias. Salvador, 18 set. 1961, $3^{\circ}$ Caderno, Suplemento Artes e Letras, p. 2 e 6. (republicado sob o título "O Barroco Viscontiano" em ROCHA, 2006a, p. 229-36).

ROCHA, Glauber. "Dois festivais e uma experiência brasileira" [entrevista a Diva Múcio Teixeira] [1962a]. Diário de Notícias. Salvador, 29 jul. 1962, $3^{\circ}$ Caderno, Suplemento Artes e Letras, p. 4.

ROCHA, Glauber. “O eclipse (o espaço funeral)” [1962b]. Diário de Notícias. 
Salvador, 2 e 3 set. 1962, $3^{\circ}$ Caderno, Suplemento Artes e Letras, p. 3-4 (republicado sob o título "Espaço funeral", em ROCHA, 2006a, p. 249-53). ROCHA, Glauber. " [Carta] para Paulo César Saraceni (abril ou maio 1963)" [1963a]. In: ROCHA, 1997, p. 190-4.

ROCHA, Glauber. "Nosso senhor Buñuel" [1963b]. Senhor. Rio de Janeiro, ano 5, n. 52-53, jun-jul. 1963, p. 60-5 (republicado sob o título "Os 10 mandamentos de Luis Buñuel", em ROCHA, 2006a, p. 170-85).

ROCHA, Glauber. Revisão crítica do cinema brasileiro [1963c]. Rio de Janeiro: Civilização brasileira, 1963, 147 p. (reed. revista e aumentada. São Paulo: Cosac \& Naify, 2003).

ROCHA, Glauber. "Vidas Secas 64" [1964a]. In: Revolução do Cinema Novo, 1981 (reed. 2004, p. 59-63).

ROCHA, Glauber. “Oito e Meio" [1964b]. Diário Carioca. Rio de Janeiro, 24 nov. 1964, p. 7 (republicado em ROCHA, Glauber, 2019, p. 143-6).

ROCHA, Glauber. Deus e o diabo na terra do sol. Rio de Janeiro: Civilização brasileira, 1965.

ROCHA, Glauber. "A presentação: A moral de um novo Cristo" [1966a]. In: KYROU, Ado (org.). Luís Buñuel. Trad. de José Sanz. Rio de Janeiro: Civilização brasileira, 1966, p. 1-8 (republicado sob o título "A moral de um novo Cristo", em ROCHA, 2006a, p. 185-90).

ROCHA, Glauber. "Glauber e a fala do Cinema Novo" [1966b]. Jornal do Brasil. Rio de Janeiro, 14 abr. 1966, Caderno B, p. 5 (republicado sob o título "O padre e a moça 66", em ROCHA, 2004, p. 78-83).

ROCHA, Glauber. [Carta] para Jean-Claude Bernardet (12/7/1967) [1967a]. In: ROCHA, 1997, p. 280-2.

ROCHA, Glauber. Tricontinental 67. [1967b]. In: ROCHA, 2004, p. 104-9 (publicação original: “Cela s'appelle aurore”. Cahiers du Cinéma, n. 195, nov. 1967, p. 39-41).

ROCHA, Glauber. "O Novo cinema no mundo. [1968a]". O Cruzeiro. Ano XL, n. 13, 30 mar. 1968 (republicado em ROCHA, 2006a, p. 343-52).

ROCHA, Glauber. "Cinema no Mundo II. Fritz Lang, o Leão" [1968b]. O Cruzeiro. Rio de Janeiro, ano XL, n. 14, 6 abr. 1968, p. 38-40 (republicado sob o título "Fritz Lang", em ROCHA, 2006a, p. 44-9).

ROCHA, Glauber. "Glauber: el 'Transe' de América Latina" [entrevista a Federico de Cárdenas e René Capriles] [1969a]. Hablemos de Cine. Lima, n. 47, mai-jun. 1969, p. 34-48 (republicado em português e sob o título “O Transe da América Latina 69", em ROCHA, 2004, p. 170-92).

ROCHA, Glauber. "Tropicalismo, antropologia, mito, ideograma 69" [1969b]. In: Revolução do Cinema Novo, 1981 (reed. 2004, p. 150-4).

ROCHA, Glauber. “América Nuestra 69". [1969c]. In: Revolução do Cinema Novo, 1981 (reed. 2004, p. 161-9).

ROCHA, Glauber. "Bad Movie ou saudades do Maciel”. O Pasquim. Rio de Janeiro, n. 76, 2 a 8 dez. 1970, p. 20-1 (republicado em ROCHA, 2006a, p. 145-8). 
ROCHA, Glauber. "Glauber Fellini - Fellini é mulher, loba, gato da Pérsia (Uma tese de Glauber Rocha)". Homem Vogue. São Paulo, agosto 1977, p. 54-60 (republicado sob o título "Glauber Fellini", em ROCHA, 2006a, p. 253-74).

ROCHA, Glauber. "O Cego que via longe 78". Folha de São Paulo, 16 set. 1978, Ilustrada, p. 28 (republicado em ROCHA, 2004, p. 367-9).

ROCHA, Glauber. "Idade da terra: um aviso aos intelectuais" [1980a]. Folha de São Paulo, 9 nov. 1980, p. 51.

ROCHA, Glauber. "Neves Eulálio David 80" [1980b]. In: Revolução do Cinema Novo, 1981 (reed. 2004, p. 405-8).

ROCHA, Glauber. "Andrade De Pedro Joaquim 80" [1980c]. In: Revolução do Cinema Novo, 1981 (reed. 2004, p. 441-6).

ROCHA, Glauber. Revolução do cinema novo. Rio de Janeiro: Editora Alhambra; Embrafilme, 1981 (reed. revista e aumentada. São Paulo: Cosac \& Naify, 2004).

ROCHA, Glauber. O século do cinema [2006a]. Rio de Janeiro: Editora Alhambra; Embrafilme, 1983 (reed. revista e aumentada. São Paulo: Cosac \& Naify, 2006).

ROCHA, Glauber. Cartas ao Mundo. BENTES, Ivana (org. e intr..). São Paulo: Companhia das letras, 1997.

ROCHA, Glauber. Le siècle du cinéma [2006b]. Trad. du portugais par Mateus Araújo Silva. Éd. française établie par Cyril Béghin et Mateus Araújo Silva. La Crisnée: Yellow now; Magic cinéma; Cosac \& Naify, 2006. ROCHA, Glauber. Crítica esparsa (1957-1965). SILVA, Mateus Araújo (org.). Belo Horizonte: Fundação Clóvis Salgado, 2019.

SILVA, Mateus Araújo. "Alain Resnais, cardiologista da sociabilidade". In: BORGES, Cristian; CAMPOS, Gabriela; AISENGART, Ines (orgs.). Alain Resnais: a revolução discreta da memória. São Paulo; Rio de Janeiro: Centro Cultural Banco do Brasil, 2008, p. 79-82.

SILVEIRA, Walter. "Um filme de transição". In: ROCHA, Glauber. Deus e o diabo na terra do sol. Rio de Janeiro: Civilização brasileira, 1965, p. 173-82. XAVIER, Ismail. "Prefácio". In: ROCHA, Glauber. O século do cinema (reed.). São Paulo: Cosac \& Naify, 2006, p. 9-31.

Recebido em 26 de maio de 2020

Aprovado em 27 de maio de 2020

131 | E N S A I O S : HIROSHIMA MON AMOUR: 60 ANOS 
Mateus Araújo é doutor em Filosofia pela Sorbonne e pela Universidade Federal de Minas Gerais. É professor livre-docente de teoria e história do cinema na Escola de Comunicação e Artes da Universidade de São Paulo, ensaísta e tradutor. Na área do cinema, organizou ou coorganizou os livros Glauber Rocha /Nelson Rodrigues (2005), Jean Rouch 2009: retrospectivas e colóquios no Brasil (2010), Straub-Huillet (2012), Charles Chaplin (2012), Jacques Rivette (2013), Godard inteiro ou o mundo em pedaços (2015), O cinema interior de Philippe Garrel (2018), Glauber Rocha: crítica esparsa (2019) e Glauber Rocha: o nascimento dos deuses (2019). Tem artigos publicados em Film Quarterly, Cahiers du Cinéma, Novos Estudos Cebrap, Clássica, Kriterion, Devires, Eco-pós, Cinemais, La Fúria Umana, entre outras. Traduziu Glauber Rocha na França (Le Siècle du Cinéma, 2006) e uma série de autores franceses no Brasil. É editor da revista Devires, da Universidade Federal de Minas Gerais. Contato: araujo.silva@wanadoo.fr

ORCiD: https:/ / orcid.org/0000-0002-4232-5423 